\title{
A SEQUÊNCIA BÁSICA E O CÍRCULO DE LEITURA COMO PRÁTICA NA EDUCAÇÃO DE JOVENS E ADULTOS POR MEIO DO CONTO FASTÁSTICO REGIONAL
}

\author{
THE BASIC SEQUENCE AND THE CIRCLE OF READING AS PRACTICE IN \\ EDUCATION OF YOUTH AND ADULTS BY REGIONAL FASTASTIC TALE
}

\section{Ivonildo da Silva Reis ${ }^{1}$}

Resumo: Atividades de leitura envolvendo o texto literário ainda se fazem pouco presentes nas salas de aula de nosso país. Tendo como base essa realidade, propomos aqui a análise do conto O Guajara (SALGUEIRO, 2011), pertencente ao estilo regional e fantástico. Nosso campo de ação é uma turma da Educação de Jovens e Adultos do nível fundamental de ensino, a qual funciona na cidade de Quixeramobim, estado do Ceará. Nosso trabalho é composto por uma pesquisa bibliográfica e discussão a partir de autores como Cotázar (2006) e Pinheiro (2008) e por uma atividade de leitura elaborada a partir de elementos da sequência básica e do círculo de leitura, explicitados em Cosson (2006). Concebemos a compreensão e interpretação do texto como um fazer coletivo, de modo que a interação entre aluno e professor é o procedimento fundante desta prática pedagógica. Um dos caminhos apontados para despertar o interesse pelo texto literário e o prazer por este proporcionado está alicerçado na necessidade de valorizar os saberes culturais do aluno, partindo da região em que ele está inserido, como verificamos através dos resultados da aplicação de nossa proposta de atividade enfocando a literatura cearense no Brasil.

Palavras-chave: Conto; Círculo de leitura; Sequência básica.

Abstract: Reading activities involving the literary text still make little present in the classrooms of our country. Based on this reality, we propose here the analysis of the short story O Guajara (SALGUEIRO, 2011), belonging to the regional and fantastic style. Our field of action is a group of youth and adult education at the elementary level of education, which operates in the city of Quixeramobim, state of Ceará. Our work is composed of a bibliographical research and discussion from authors such as Cotázar (2006) and Pinheiro (2008) and a reading activity elaborated from elements of the basic sequence and reading circle, explained in Cosson (2006) . We conceive the understanding and interpretation of the text as a collective doing, so that the interaction between student and teacher is the founding procedure of this pedagogical practice. One of the ways pointed out to arouse interest in the literary text and the pleasure it provides is based on the need to value the cultural knowledge of the student, starting from the region in which he is inserted, as we verified through the results of the application of our activity proposal focusing on the literature of Ceará in Brazil.

Keywords: Tale; Reading circle; Basic sequence.

\footnotetext{
11 Mestrando em PROFLETRAS - Universidade Estadual do Ceará (UECE). Professor de Língua Portuguesa no Centro de Educação de Jovens e Adultos Alfredo Almeida Machado. E-mail: ivonildo.reis@hotmail.com
} 


\section{Introdução}

O presente trabalho trata da leitura de um conto do universo fantástico, com características da literatura regional cearense, direcionado a alunos da Educação de Jovens e Adultos no nível fundamental II de ensino. Propomos uma atividade de leitura, utilizando procedimentos da sequência básica e do círculo de leitura (COSSON, 2006), a partir do conto O Guajara, do escritor, Florival Seraine, presente no livro O Cravo Roxo do Diabo (SALGUEIRO, 2011).

Desenvolver a leitura em nossas escolas torna-se uma prática extremamente relevante num mundo grafocêntrico como o nosso. A função precípua das escolas é oportunizar o contato com o mundo da leitura, haja vista que dessa depende a aquisição de vários outros saberes, tornando-se assim ponto de referência na construção e interpretação do mundo (BRASIL, 1998). Mas não é só na escola que saber ler se torna tão importante; inúmeras atividades sociais se valem do universo escrito para se desenvolverem, desde a simples decodificação de um aviso ao posicionamento crítico diante de notícias e reportagens. Outro aspecto a ser considerado é a necessidade humana estética oportunizada pelo texto literário (ALVES, 2000). Nesse sentido, é função da literatura " [...] tornar o mundo compreensível transformando a sua materialidade em palavras de cores, odores, sabores e formas intensamente humanas" (COSSON, 2006, p. 17) A partir dessa necessidade social e pessoal, pergunta-se: a escola tem incentivado a leitura? Enquanto professores de Língua Portuguesa, percebemos que as práticas escolares ainda se têm voltado muito para o ensino prescritivo da língua, cujo objetivo se traduz em fazer com que o estudante substitua suas formas de pensar e se expressar por padrões considerados aceitáveis de acordo com normas impostas.

Tendo por base a necessidade de criar oportunidades para o desenvolvimento do hábito de ler, elaboramos uma atividade de leitura, em que partimos de um texto que envolve o universo regional dos alunos, muitas vezes lembrando histórias orais que os estudantes talvez conheçam. Esse aspecto reforça a ideia de que "é fundamental manter-se de olhos e ouvidos abertos, atento à vivência cultural da comunidade em que a escola está inserida" (PINHEIRO, 2008, p. 19). Corrobora ainda essa afirmação, o que nos diz Pinheiro ao falar sobre a literatura popular na escola: "Referimo-nos, especificamente, a um tipo de experiência que não visa o insólito, mas que busca, de fato, uma aproximação com a experiência do outro para também reconhecer-se e aprender com esta experiência" (PINHEITO, 2008, p. 25).

Como se trata de uma atividade direcionada primeiramente a alunos da Educação de Jovens e Adultos, optamos por trabalhar com o conto, narrativa curta, haja vista as dificuldades 
de leitura apresentadas por esse público. As etapas da atividade totalizaram $08 \mathrm{~h} / \mathrm{a}$, envolvendo os perfis de leitor do círculo de leitura e da sequência básica (COSSON, 2006).

\section{0 texto literário em sala de aula}

Diante da função social da escola de proporcionar o acesso à leitura, cabe-nos saber qual o papel da literatura no processo de desenvolvimento leitor dos alunos. Os Parâmetros Curriculares Nacionais, do terceiro e quarto ciclo do Ensino Fundamental, apontam que se deve proporcionar aos alunos condições para que estes tenham: "interesse pela leitura como fontes de informação, aprendizagem, lazer e arte (grifo nosso); interesse pela literatura (grifo nosso), considerando-a como forma de expressão da cultura de um povo." (BRASIL, 1998, p. 64).

Percebemos assim que a didática da leitura não pode estar atrelada apenas a aspectos pragmáticos, ou seja, somente ligada a aspectos cotidianos e práticos; ela deve proporcionar, além do conhecimento utilitarista, a fruição do artístico, característica fundamental da literatura. Partindo-se dessa premissa, precisamos criar oportunidades para o trabalho com o texto literário no ensino fundamental que contribuam para que ler seja fonte de conhecimento e prazer (CANDIDO, 2002).

É preciso compreender que grande parte dos processos interpretativos envolvendo textos que se utiliza fora da escola foram aprendidos dentro dela, daí porque a importância de um trabalho efetivo com a literatura em sala de aula por parte do professor de Língua Portuguesa. A escola tem a função de trabalhar o conhecimento e essa concepção deve perpassar o letramento literário. Não se trata de mecanizar as atividades que envolvem o fazer pedagógico, impedindo a fruição, tão cara à literatura. Mas é preciso que o professor esteja atento ao fato de que trabalhar com textos literários envolve proporcionar condições para que o aluno aprenda efetivamente e possa sentir que a literatura envolve a cultura de um povo.

Nessa perspectiva, é preciso que os professores se valham de atividades estimulantes e significativas para que ler literatura contribua para a formação global e leitora dos alunos. Tarefas do tipo "preenchimento de ficha de leitura", tão ainda presentes nas salas de aula do ensino fundamental, já se mostraram pouco eficientes, pois tornam o contato com a literatura algo mecânico, como um jogo em que o aluno caça nos livros a resposta para determinada questão proposta. Ademais, na era da internet, em que as informações são ilimitadas, muitos apenas se utilizam do "copiar, colar", satisfazendo assim a uma concepção apenas utilitarista para o preenchimento de um questionário e uma atribuição de nota. 
Contrapondo-se à ideia de reduzir a leitura a esse tipo de atividades, temos

Precisamos, portanto, compreender a leitura como uma arte para, depois, pragmaticamente, despertar o prazer da leitura em meio à crise da palavra escrita. Precisamos compreender, ainda, como se aprende a ler e o que há de fantástico na leitura para reeducar leitores fracassados e chegar a um nível de leitura eficaz. (COSTA; FERREIRA, 2006, p, 51)

Precisamos, portanto, compreender a leitura como uma arte para, depois, pragmaticamente, despertar o prazer da leitura em meio à crise da palavra escrita. Precisamos compreender, ainda, como se aprende a ler e o que há de fantástico na leitura para reeducar leitores fracassados e chegar a um nível de leitura eficaz. (COSTA; FERREIRA, 2006, p, 51).

Eis que se verifica um ponto fundamental para o trabalho com o texto literário: a fruição estética. Tal perspectiva se mostra um grande desafio para nosso fazer docente, o que aponta para a necessidade de um planejamento cuidadoso, utilizando recursos didáticos diversos. Além disso, é preciso estar atento a dois pontos: selecionar textos que estejam no nível de escolaridade do aluno e que estes textos possam atrair a sua atenção.

Outro ponto a ser discutido é o trabalho coletivo com o texto literário. É no trabalho interativo que os diversos sentidos vão sendo (re)construídos, em que as visões de mundo se entrelaçam e se ampliam. Confirmando essa ideia, temos:

"O bom leitor, portanto, é aquele que agencia com os textos os sentidos do mundo, compreendendo que a leitura é um concerto de muitas vozes e nunca um monólogo. Por isso, o ato físico de ler pode até ser solitário, mas nunca deixa de ser solidário." (COSSON, 2006, p. 26).

Para o trabalho com literatura em sala de aula, Cosson (2006, p. 32-33) nos aponta quatro questões a serem levadas em conta na análise que se faz da seleção dos textos: as finalidades educativas, a adequação à série escolar ou faixa etária, as condições físicas da escola e, por fim, a mais importante: as leituras do professor. Este último fator nos aponta para a intimidade que o professor teve/tem com a leitura. Não se pode formar leitores se o educador não é, ele mesmo, um leitor proficiente. Muita da experiência do professor com o texto literário irá subsidiá-lo na sua prática e isso é um fator preponderante nas atividades leitoras desenvolvidas por ele.

A noção da diversidade social se estende também à seleção dos textos a serem trabalhados pelo professor. Cosson (2006, p. 33), depois de indicar o critério dos cânones e contemporaneidade, assim nos aponta

A mais popular das direções seguidas parece ser aquela que defende a pluralidade e a diversidade de autores, obras e gêneros na seleção de textos. Ela está apoiada nas 
recomendações dos textos oficiais sobre o ensino da área de linguagem e nas teorias da leitura como uma habilidade a ser construída pelo trânsito intenso de textos diferenciados em sua configuração discursiva e genérica dentro da escola.

A mais popular das direções seguidas parece ser aquela que defende a pluralidade e a diversidade de autores, obras e gêneros na seleção de textos. Tal encaminhamento está apoiado nas recomendações dos textos oficiais sobre o ensino da área de linguagem e nas teorias da leitura como uma habilidade a ser construída pelo trânsito intenso de textos diferenciados em sua configuração discursiva e genérica dentro da escola.

Defendemos, em consonância com as ideias de Cosson (2006), que esses três critérios não são excludentes e devem sempre ser levados em conta no ato pedagógico. Nessa perspectiva da diversidade do letramento literário, concordamos também com Pinheiro (2013, pp. 35, 36): "Em princípio, não negamos o cânone, antes, achamos que ele necessita ser ampliado, incluindo em seu corpus, entre outras manifestações, parte significativa da literatura de origem popular."

Dessa forma, nosso trabalho está ancorado na pluralidade e no reconhecimento da cultura popular para o desenvolvimento das atividades didáticas a serem propostas pelo professor de Língua Portuguesa.

\section{A literatura popular e os contos fantásticos}

Despertar a atenção e o gosto pela leitura em sala de aula é um dos principais objetivos nas aulas de Língua Portuguesa. Em nossa prática educativa, temos percebido que os níveis de leitura e compreensão dos alunos estão muito aquém desse objetivo, o que nos faz voltar a atenção para a necessidade de se planejar atividades que cumpram o papel de estimular o contato com o texto literário como fruição e conhecimento cultural. Pensando na conjugação desses dois aspectos, optamos por trabalhar o conto fantástico de cunho regional cearense $\mathrm{O}$ guajara, cuja narrativa se passa no estado onde se dá nossa prática profissional.

Segundo Koch (2003), ao selecionar um texto, o professor precisa atentar para a necessidade de o aluno compreender o gênero escolhido para melhor apreciá-lo ou compreendêlo. A atividade aqui desenvolvida numa turma de EJA, além de tentar proporcionar o prazer advindo do contato com o texto literário, vale-se com as do gênero conto, narrativa curta, com um núcleo dramático, personagens e espaços reduzidos. A brevidade é uma das características fundamentais do conto, como nos diz Cortázar (2006, p. 150): "uma síntese viva ao mesmo tempo que uma vida sintetizada, algo assim como um tremor de água dentro de um cristal, uma fugacidade numa permanência." 
A literatura fantástica, ao lidar com o sobrenatural, vale-se de símbolos que fazem parte do nosso universo dito real, assim como os demais textos literários. Martha (2008, p. 18) assim nos confirma essa concepção: "Ler ficção e poesia, por conseguinte, não é entrar num mundo mágico, irreal e alienado, mas captar a realidade mais intangível, aquela sedimentada no imaginário a partir das ingerências do cotidiano da história individual e social".

Valorizar a cultura regional, através do texto literário, é uma tentativa de reverter a situação descrita por Pinheiro (2013, p. 16): "quando há a presença da cultura popular no trabalho de algumas escolas e até mesmo de secretarias de educação, muitas vezes a concepção que se tem é de resgate de algo que já teria morrido".

Salientamos que a cultura é um elemento vivo, dinâmico, formada por pessoas e formadora de pessoas. Está assim dentro da concepção de diversidade, seu reconhecimento e valorização.

\section{A sequência básica e o círculo de leitura}

Essas duas propostas de trabalho com o texto literário são apresentadas por Cosson (2006) e privilegiam a interpretação, ao invés, por exemplo, de uma abordagem voltada para a crítica e história literárias, estudos pautados no conhecimento acadêmico que privilegia o contexto histórico ou o valor artístico das obras, muitas vezes sem se valer da interpretação do texto literário. O autor defende a "aprendizagem da literatura, que consiste fundamentalmente em experienciar o mundo por meio da palavra" (COSSON, 2006, p. 47). Para oportunizar essa experiência, aponta para a necessidade de sistematizar os procedimentos com o texto literário de modo que o contato com este se torne uma prática significativa para o aluno, para o professor e para o contexto social em que se inserem. A sistematização sugerida pelo autor está expressa em sequência básica e círculo de leitura.

Abaixo descrevemos resumidamente a sequência básica, segundo Cosson (2006, p. 5467), a qual apresenta elementos que fazem parte da proposta de trabalho por nós delineada:

- Motivação: momento de preparação para a análise da obra; geralmente envolve a formulação de uma questão ou o posicionamento diante de um tópico abordado pelo texto;

- Introdução: apresentam-se, nessa etapa, autor e obra;

- Leitura: muda a depender da extensão do texto, com procedimentos distintos por parte do professor e alunos; 
- Interpretação: ponto nevrálgico da metodologia, consiste numa série de ações que visam à construção de sentido como ato interno (pessoal) e externo (social);

- Extrapolação: momento em que a interpretação do texto transcende, adquirindo outras formas de expressão criativa por parte do leitor.

O círculo de leitura insere-se na categoria de comunidade leitora. O autor nos descreve seus tipos, a saber: círculo estruturado, semiestruturado, aberto ou não estruturado. Aqui optamos por utilizar elementos do primeiro tipo, notadamente os papeis a serem desempenhados pelos alunos num roteiro de discussões. Essas funções são, segundo Cosson (2006, p. 142-143):

- Conector - relaciona a obra com a vida;

- Questionador - prepara perguntas analíticas, por exemplo, sobre personagens, acontecimentos etc;

- Iluminador de passagens - seleciona um momento da obra para salientar sua importância, dificuldade de compreensão ou por sua beleza;

- Ilustrador - usa imagens para ilustrar o texto;

- Dicionarista - seleciona palavras que podem ser difíceis para o grupo;

- Sintetizador - faz o sumário da obra;

- Pesquisador - busca elementos do contexto (histórico, social, econômico etc) que influem na compreensão do texto;

- Cenógrafo - detalha as cenas principais;

- Perfilador - faz um perfil dos principais personagens.

A atividade desenvolvida mescla elementos das duas propostas de trabalho (sequência básica e círculo de leitura) explicitados em Cosson (2006), conforme é descrito no próximo tópico.

\section{Proposta de atividade}

A atividade foi desenvolvida seguindo os passos descritos a seguir.

\subsection{Motivação}


De acordo com Cosson (2006, p. 54), "o sucesso do encontro do leitor com a obra depende de boa motivação". Trata-se de um momento em que o professor levanta temas, posicionamentos ou outros aspectos relacionados ao texto a ser estudado.

Em nosso caso, como lidamos fundamentalmente com o universo fantástico, em que medos e tensões são evocados, optamos por motivar os estudantes por meio de um pequeno vídeo que aborda essas sensações e sentimentos intitulado: O lobisomem e o coronel, disponível em https://www.youtube.com/watch?v=qLTzbfopMmE.

O vídeo foi selecionado porque mantém uma íntima relação temática, linguística (variação regional) com o texto a ser lido pelos alunos e por estabelecer uma coerência com o que defendemos neste trabalho, a valorização da cultura regional. A linguagem do cordel, o ambiente, os personagens, até mesmo elementos decorativos, como um quadro do Padre Cícero na parede, retratam esse universo.

Depois de o vídeo ser visto, fizemos as seguintes perguntas: Vocês acreditam que existem seres sobrenaturais, como o que aparece na história assistida? De que outros personagens vocês já ouviram falar? A etapa de motivação deve ser breve para não abranger outras etapas da sequência básica.

\subsection{Introdução}

Essa etapa corresponde à apresentação do texto e de seu autor. Fizemos um breve comentário sobre a organização da obra, composta de 172 contos, 60 poemas e 17 trechos de romance com a temática do fantástico, cujos enredos se passam no estado do Ceará. Apesar de contar com dois outros gêneros literários, é o conto que consta no subtítulo do livro. Deve-se salientar que as histórias são de diferentes escritores de diferentes épocas, bem como deixar em evidência o trabalho de pesquisa dos organizadores.

Nesta etapa, é importante suscitar questões que serão abordadas mais adiante. Sugerimos: o que é um conto? O que são contos fantásticos? Pede-se que os alunos pesquisem e tragam suas conclusões nas aulas dedicadas à interpretação.

É importante proporcionar o contato físico com a obra, fazendo com que ela circule entre os alunos. Esse é o momento de explorar os elementos da capa, através de perguntas tais como: quais cores predominam nela? Por quê? Que figuras fazem parte dela? Novamente, as respostas a essas perguntas não devem ser muito discutidas nesse momento. O objetivo aqui é instigar a curiosidade do aluno. 
Fig 1. Capa do livro O Cravo Roxo do Diabo

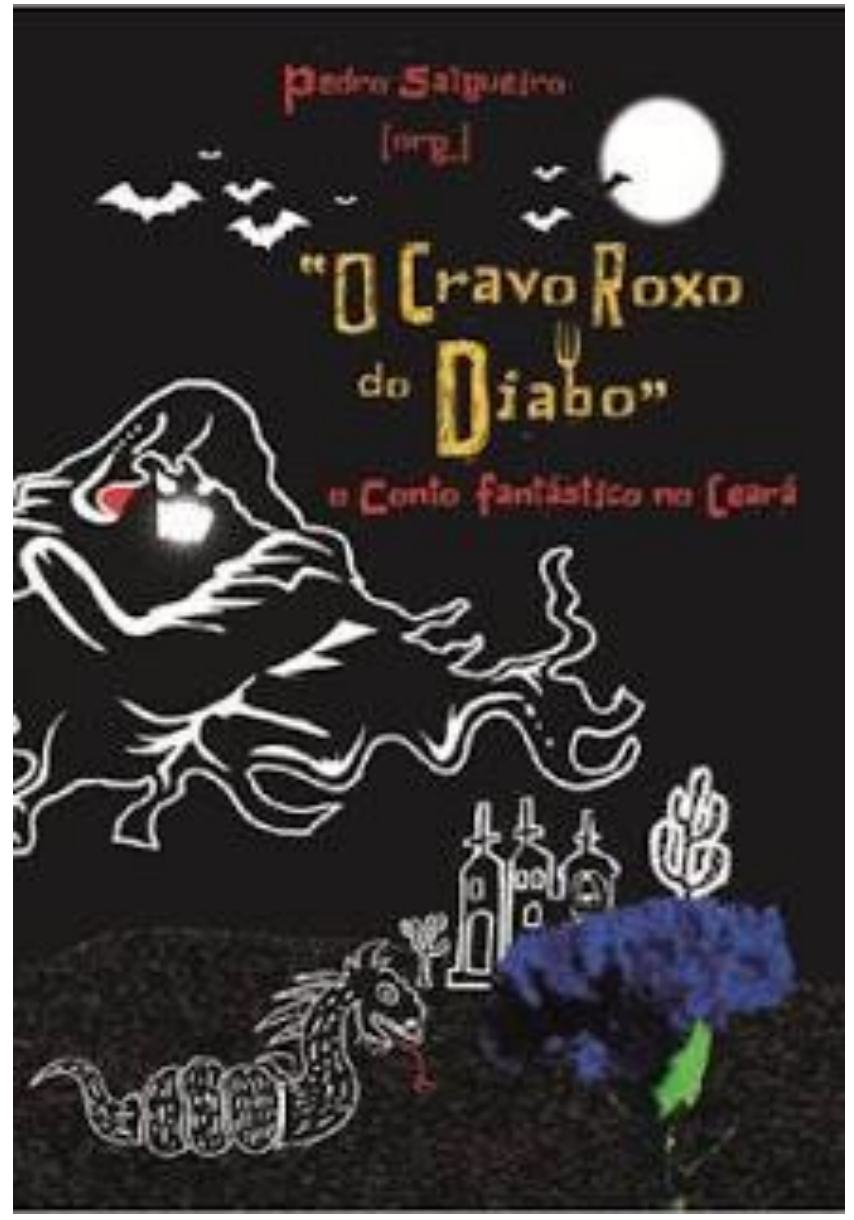

FONTE: SALGUEIRO, Pedro (Org.). O Cravo Roxo do Diabo. Expressão Gráfica Editora. Ceará: 2011.

Na sequência, informamos que será feita a leitura de um dos contos presentes na obra: $\mathrm{O}$ guajara, de Florival Seraine. Resumidamente, demos algumas informações sobre este autor: nasceu no Pará, formou-se como médico e exerceu a profissão de professor na Universidade Federal do Ceará, dando inclusive aulas sobre folclore; viveu entre 1910 a 1999. Também se deve perguntar sobre o título do conto: vocês sabem o que significa o termo "Guajara"? Após isso, não demos a resposta, suscitando a dúvida. Informamos que vamos descobrir com a leitura do conto.

\subsection{Leitura}

Nessa etapa, cada aluno recebeu uma cópia do conto. A turma foi dividida em pequenos grupos para a leitura. Sugerimos que esta seja realizada por parágrafos para que todos participem da ação. 


\section{4 Interpretação}

Iniciamos essa etapa retomando e discutindo as duas perguntas feitas na introdução: o que é um conto? O que são contos fantásticos? Com o resultado das pesquisas, relacionamos as respostas ao conto lido.

A partir desse momento, a turma continua dividida em grupos e apresenta as funções do círculo de leitura: a) conector; b) questionador; c) iluminador de passagens; d) ilustrador; e) dicionarista; f) sintetizador; g) pesquisador; h) cenógrafo; i) perfilador (COSSON, 2006, p. 42143). Para proporcionar um ambiente mais democrático, realizamos um sorteio dessas funções entre os alunos.

Foram distribuídas fichas com perguntas, de acordo as funções descritas. Depois de preenchidas essas fichas, as equipes se apresentaram, sendo que tivemos o cuidado de proporcionar a interação entre os participantes, através de perguntas e observações.

Se formado mais de um grupo, sugerimos que as apresentações sejam divididas. Por exemplo, do grupo 1, apresentam-se quatro funções e do outro, cinco, sendo que as funções de conector, questionador, iluminador e ilustrador devem ser igualmente distribuídas entre os grupos, pois estão ligadas a um tipo de leitor mais proficiente.

\subsection{Extrapolação}

Nesse campo, propusemos que os alunos pesquisassem uma história da comunidade local com traços do fantástico e escrevessem essa narrativa. Sugerimos que fizessem isso em dupla. Seria interessante que os mesmos realizassem entrevistas com moradores locais, amigos, pessoas da família. Os próprios alunos provavelmente já devem ter alguma dessas histórias em sua memória, sendo preciso talvez dar verossimilhança aos elementos formais do conto, como personagens, espaço, tempo, enredo, clímax, o que será feito pelo professor e aluno quando da revisão dos textos. Tal revisão foi feita através de diálogos entre professor e as duplas. Pedimos que tentassem, a exemplo do conto base da atividade, utilizar, nas falas dos personagens, a linguagem da região em que se passa a história. Também, solicitamos que os alunos ilustrassem essa produção textual.

Esses contos foram a base para a criação de um livro em forma de coletânea, assim como o livro de onde foi retirado o conto analisado. Sugerimos, assim como realizado por nós, que o lançamento da obra seja um evento da escola, aberto à comunidade, especialmente dos entrevistados e familiares dos alunos, proporcionando a interação entre o ambiente escolar e a 
o espaço social em que se encontra. Feito isso, estamos valorizando os saberes dos estudantes e do meio em que vivem, além de darmos um caráter social à leitura e produção de textos.

\section{Análises e resultados}

As discussões teóricas empreendidas e a atividade de leitura aplicada em sala de aula nos mostraram a grande necessidade de repensarmos a didática utilizada nas escolas como uma das incentivadoras à prática leitora.

Ao desenvolvermos a atividade de leitura sugerida neste artigo no Centro de Educação de Jovens e Adultos, cidade de Quixeramobim, verificamos o engajamento da turma e o seu interesse pelo conto sugerido. Acreditamos que um dos motivos para o interesse dos alunos resida no fato de o mesmo abordar uma região e linguagem que são suas e por tratar de uma tradição bem conhecida por eles, o das histórias de assombração. Não foi difícil os estudantes relembrarem "causos" que seus pais já contavam e os mesmos se identificarem com a linguagem usada pelos personagens do conto. Isso também serviu para que vissem que a sua variante linguística pode ser escrita, caracterizando uma cultura.

Após as leituras nos grupos, todos os alunos foram reunidos para a discussão do conto, a partir das observações feitas pelos estudantes responsáveis pelas funções do círculo de leitura. Nossa intervenção se deu no processo de interpretação da obra. Durante a apresentação dos dicionaristas, foi questionado o motivo de a ortografia oficial não ter sido respeitada no conto. Interviemos explicando que o uso da linguagem pelos personagens confere maior verdade a eles, pois mostra como falam. Ao mesmo tempo, mostramos que, quando o narrador se expressa, usa a linguagem formal.

O fato de reunirmos os contos produzidos pelos alunos e os publicar em forma de livro ganhou relevância social e fundamentou a concepção de que o texto produzido tem um objetivo, não sendo apenas mais uma tarefa escolar sem concretude, afinal esses estudantes entraram na cadeia de produção artística: autor/obra/leitor.

\section{Considerações finais}

A partir das discussões e análises realizadas, percebemos a validade de se trabalhar com a leitura do texto literário, partindo da realidade cultural do aluno. Vimos que a discussão sobre a linguagem usada nesses contos se constitui como caracterização dos personagens, ligando-os à região os estudantes vivem. 
Preocupamo-nos em trabalhar com o texto literário, especificamente o conto, a partir de dois traços: o regional e o fantástico. Acreditamos que a cultura do lugar em que o aluno vive deva ser um elemento fundamental a ser trabalhado no espaço escolar, como reconhecimento de que os saberes não se dão apenas por canais formais, como a literatura e a história oficias, mas que podem ser construídos também através do resgate da cultura popular. Esse saber está presentes, por exemplo, na literatura dos causos, contadas por gerações. Além disso, histórias que mexem com as emoções, como o medo, o suspense, características do universo fantástico, são também formas de atrair o estudante para o mundo da leitura.

Tomando como base a atividade sugerida, utilizando a sequência básica e o círculo de leitura, preocupamo-nos em focalizar o contato prazeroso do aluno com a obra literária, proporcionando uma didática que valoriza a interpretação da mesma e a oportunidade de, a partir dela, pesquisar e se tornar autor de seu próprio texto.

\section{Referências}

ALVES, Rubem. Entre a ciência e a sapiência: o dilema da educação. 4. ed. São Paulo: Loyola, 2000.

BRASIL. MEC. Parâmetros curriculares nacionais - terceiro e quarto ciclos do ensino fundamental. Brasília, MEC/SEF, 1998.

CANDIDO, Antonio. A literatura e a formação do homem. In: . Textos de intervenção. São Paulo: Duas cidades/Editora 34, 2002.

CORTÁZAR, Julio. Alguns aspectos do conto e Do conto breve e seus arredores. In Valise de Cronópio. Trad. Davi Arrigucci Jr. E João Alexandre Barbosa. São Paulo: Perspectiva, 2006.

COSSON, Rildo. Letramento literário: teoria e prática. São Paulo: Contexto, 2006.

COSTA, Maria Edileuza da; FERREIRA, Maria Aparecida da Costa Gonçalves. O prazer da literatura: o uso do texto literário em sala de aula. Revista das Letras - $\mathrm{N}^{\mathrm{o}} 28$ - Vol. 1/2 Jan/Dez. 2006.

KOCH, Ingedore Grunfeld Villaça. Desvendando os segredos do texto. 2. ed. São Paulo, Cortez: 2003.

MARTHA, Alice Áurea Penteado (org.). Leitor, leitura e literatura - teoria, pesquisa e prática: conexões. Maringá: Eduem, 2008.

PINHEIRO, Helder. Literatura popular e ensino: leituras, atitudes e procedimentos. In: SILVA, Maria Valdênia da; NETO, Leocádio Araújo Araújo; PEREIRA, Jaquelânia Aristides; PINHEIRO, Hélder. (Orgs). Leitura e formação de leitores. Campina Grande: Bagagem, 2008. 
Helder. O que ler? Por quê? A literatura e seu ensino. In: DALVI, Maria Amélia, REZENDE, Neide Luzia de, JOVER-FALEIROS, Rita (Orgs). Leitura de literatura na escola. São Paulo: Parábola, 2013.

SALGUEIRO, Pedro (Org.). O cravo roxo do diabo. Fortaleza, Expressão Gráfica, 2011.

Recebido em 28 de dezembro de 2017. Aceito em 17 de setembro de 2018. 